\title{
Metabolic Reponses to a physical exercise session in women with excess body mass: randomized clinical trial
}

Djeyne Silveira Wagmacker ${ }^{1,2,4^{*}}$ (D), Jefferson Petto ${ }^{1,2}$, Amanda Silva Fraga $^{2}$, Jackeline Barbosa Matias ${ }^{1}$, Sindy Kerole Andrade Mota' ${ }^{1}$ Luiz Erlon Araujo Rodrigues ${ }^{2}$ and Ana Marice Ladeia ${ }^{2,3}$

\begin{abstract}
Background: There are various factors that influence the effect of physical exercise on the lipid profile, among them the body mass index and calorie expenditure of the exercise are some of the main factors. To test the hypothesis that a physical exercise session based on caloric expenditure may acutely modify the glycemia and lipid values of women with excess body mass.

Methods: The study included 66 women, randomly divided into two groups, control and experimental, with BMl of $29 \pm 4.4 \mathrm{~kg} / \mathrm{m}^{2}$ vs $29 \pm 4.3 \mathrm{~kg} / \mathrm{m}^{2}(p=0.45)$ sedentary and aged $23 \pm 3.8 \mathrm{vs} 24 \pm 3.5$ years, respectively $(p=0.25)$. After $12 \mathrm{~h}$ fasting, the volunteers underwent the first blood collection. The experimental group was submitted to a physical exercise session corresponding to energy expenditure of $250 \mathrm{Kcal}$, of light intensity based the Borg Rating of Perceived Exertion (RPE), $12 \mathrm{~h}$ after the first blood collection. The control and experimental group volunteers underwent a second blood collection $24 \mathrm{~h}$ after the first. Glycemia, insulin status and lipid profile were measured and Homa IR and Homabeta were calculated. The t-test for independent and dependent samples was used, and a level of significance of 5\% was adopted.
\end{abstract}

Results: Physical exercise changed the glycemic response in both the intragroup analysis (before $=96 \pm 6.6 \mathrm{mg} / \mathrm{dL}$ vs after $=92 \pm 6.6 \mathrm{mg} / \mathrm{dL}$ ), $(p=0.01)$, and in the intergroup analysis (control $=\Delta 0.9 \pm 6.1 \mathrm{vs} \mathrm{experimental}=\Delta-4.1 \pm 6.3$ ) $(p=0.02)$. No changes were shown for the Homa IR, Homa Beta and Insulin indexes. When the lipid profiles were evaluated, differences in HDL were shown in the intragroup analysis (before $=89 \pm 10.5 \mathrm{mg} / \mathrm{dL}$ vs. after $=91 \pm 10.3 \mathrm{mg}$ / $\mathrm{dL})(p=0.04)$. For the other parameters (LDL, TG, Total Cholesterol, TG/HDL), no changes were shown.

Conclusion: In women with excess body weight, a low intensity exercise session diminished the glycemia, but did not change the lipid response.

Trial registration: NCT03170973. Retrospectively registered.

Keywords: Obesity, Motor activity, Lipids, Glycemia

\footnotetext{
* Correspondence: djeyne@hotmail.com.br

${ }^{1}$ College Adventist Bahia, Cachoeira, Bahia, Brazil

${ }^{2}$ Bahian School of Medicine and Public Health, Science Development

Foundation of Bahia, Bahia, Brazil

Full list of author information is available at the end of the article
} International License (http://creativecommons.org/licenses/by/4.0/), which permits unrestricted use, distribution, and reproduction in any medium, provided you give appropriate credit to the original author(s) and the source, provide a link to the Creative Commons license, and indicate if changes were made. The Creative Commons Public Domain Dedication waiver (http://creativecommons.org/publicdomain/zero/1.0/) applies to the data made available in this article, unless otherwise stated. 


\section{What does this study add?}

- No clinical trial evaluating the acute effect of physical exercise based on energy expenditure on the metabolism of women with altered body weight was identified.

- The results on the effect of acute exercise on metabolism have not yet been fully elucidated with divergent conclusions.

\section{Background}

Various studies have evaluated the acute and chronic effects of physical exercise on metabolic variables $[1,2]$. The large majority of these studies have observed that physical exercise was an efficient therapy regulating both the lipid and glycemic profiles.

More specifically, the effects of a single session of physical exercise have also been the object of study of some researches [3-5]. Along this line, there is a strong counter point between the studies, since some have shown positive effects, while other pointed out no changes in the lipid or glycemic profiles with only one session $[4,5]$.However, all the studies that have evaluated the effect of a single exercise session on the metabolic response, raised the hypothesis that there are various factors that influence the results, such as: the clinical condition and previous functional capacity of the participants, and the characteristics of the exercise applied. Moreover, it is known that one of the clinical conditions with great influence on this response is the Body Mass Index (BMI). Furthermore, it has been demonstrated that obese persons with dyslipidemia or diabetes mellitus present more positive results when compared with eutrophic populations [6, 7]. Caloric expenditure has been pointed out as being the main variable of physical exercise that determines the beneficial effect on the lipid profile [8]. Thus, the aim of this study was to test the hypothesis that a physical exercise session based on caloric expenditure may acutely modify the variables of glycemia and lipid values of women with excess body mass index.

\section{Methods}

\section{Study design and population}

This was a Randomized Clinical Trial registered in the Clinical Trial Registry with the identifier number NCT03170973. The accessible population came from the Clinic School of the "Faculdade Adventista da Bahia", in Cachoeira, BA, Brazil.

All the women registered with the Physical Therapy Service of the Clinic School who had a body mass index (BMI) above $24.9 \mathrm{~kg} / \mathrm{m}^{2}$ were invited to participate in the study. A total of 66 volunteers fulfilled the inclusion criteria, which were: age between 18 to 30 years,
BMI $>24.9 \mathrm{~kg} / \mathrm{m}^{2}$ and be sedentary. Sedentarism was determined based on the International Physical Activity Questionnaire - long version [9].

Excluded from the study were women who presented cardiovascular; metabolic disease; hypothyroidism; renal parenchymal disease or diabetes mellitus; history of alcoholism or smoking; use of hypolipemiant, corticosteroid, diuretic, beta-blocker, and contraceptive medications.

The women were randomly divided into two groups: exercise and control; both with 33 volunteers.

\section{Exercise group}

After $12 \mathrm{~h}$ fasting, the volunteers were submitted to blood collection, in the antecubital vein, to measure the basal serum values of triglycerides, total and fractionated cholesterol, glycemia and insulin. From the Glycemia and Insulin values, the Homa-IR and Homa-Beta index values were calculated by means of the equation proposed by Mathews and cols [10]. The patients were evaluated relative to diet on the two days before the blood exam, by means of a 24-h food intake diary, with a view to minimizing the effects of diet on the results.

When $12 \mathrm{~h}$ had elapsed after the first blood collection, the patients performed a physical exercise session on an ergometric treadmill. The exercise session was divided into 3 time intervals: warming-up, conditioning and cooling-off. The duration of warming-up was $7 \mathrm{~min}$; cooling off $5 \mathrm{~min}$, and conditioning time corresponded to energy expenditure of $250 \mathrm{Kcal}$ [11] with light intensity based on the Borg [12]. Rating of Perceived Exertion (RPE), that is, on the original scale - a value between 9 and 11. For better understanding of this scale, on the day before the exercise, the volunteers were familiarized with the RPE concept to allow them to get used to answering in an adequate manner when they were asked about the intensity of the exercise. A cardiac frequency meter was used, which measured the energy expenditure based on the volunteer's body mass, sex and age.

After the physical exercise session, they were instructed to go home and keep to their habitual diet. When $24 \mathrm{~h}$ had elapsed after the first blood collection, the volunteers returned to the laboratory after a $12-\mathrm{h}$ fast, and once again had blood samples collected. Once again, they were questioned about their diet on the day before the exam by means of keeping a 24-h food-intake diary.

\section{Control group}

The women in the control group were submitted to the same data collection protocol as that of the experimental group, however, they did not do the exercise $12 \mathrm{~h}$ after the first blood collection. They were instructed not to perform any physical exercise on the two days before the blood collection, as shown in the flow diagram presented below. (Fig. 1). 


\section{Blood collection and metabolic profile}

The volunteers were submitted to blood collection after fasting for $12 \mathrm{~h}$. Samples of $5 \mathrm{ml}$ of blood were collected in tubes with EDTA, and after collection the samples were centrifuged at a speed of $3000 \mathrm{rpm}$ for $10 \mathrm{~min}$.

Serum analyses were performed as follows: the blood glucose levels, triglycerides and total cholesterol were determined by the enzymatic calorimetric method; LDL was calculated by using the Friedwald [13] equation; and the Homa-IR and Homa-Beta indexes were calculated by using the equation proposed by Mathews and cols [10].

\section{Ethical aspects}

This study was submitted to the Research Ethics Committee of the Faculdade Adventista da Bahia and approved under Protocol No. 34017514.5.0000.0042. Throughout the entire study, the guidelines on research with human beings of Resolution 466/2012 of the National Health Council were observed.

\section{Statistical analysis}

The data were previously analyzed by the Shapiro-Wilk test, with regard to symmetry. For characterization of the following variables: BMI, age, HOMA-IR, HOMA-beta, Insulin, glycemia, TG, CT, HDL, LDL and TG/HDL, the mean and standard deviation or median and interquartile interval were used, depending on the behavior of the variable. The level of significance was defined by the value of $p<0.05$.
For comparison of the effects of exercise on the glycemic, lipid and inflammatory profiles, inter- and intragroup comparisons were made by using the paired and non-paired Student's- $t$ test in cases of symmetry, and the Mann-Whitney and Wilcoxon Signed-Rank tests in cases of non-parametric data. The data were analyzed by using the Statistical Package for the Social Sciences (SPSS) software program, version 14.0.

\section{Results}

This study included 66 young women, aged $24 \pm 3.6$ years, with BMI $29 \pm 4.3 \mathrm{Kg} / \mathrm{m}^{2}$, with lipid and glycemic profiles within the values of normality.. Metabolic values do not differ between the experimental and control groups except for the insulin and Homa values that are higher in the control group. The clinical characteristics are described in Table 1.

In the intragroup analysis, a decrease in serum glycemia $(96.7 \pm 6.6$ vs $92.6 \pm 6.6 \mathrm{mg} / \mathrm{dl})(p=0.01)$ was observed in experimental group, only. No difference was demonstrated for the others variables in both groups (Table 2).

When the intergroup glycemic profile variation was analyzed, the decrease of glucose was lower in the experimental group. No difference was observed in insulin level, insulin resistance and insulin sensitivity between groups. (Table 3).

The intra-group analysis of lipid profile, showed a significant increase in the HDL values and a tendency to decrease in the TG/HDL ratio in the exercise group,

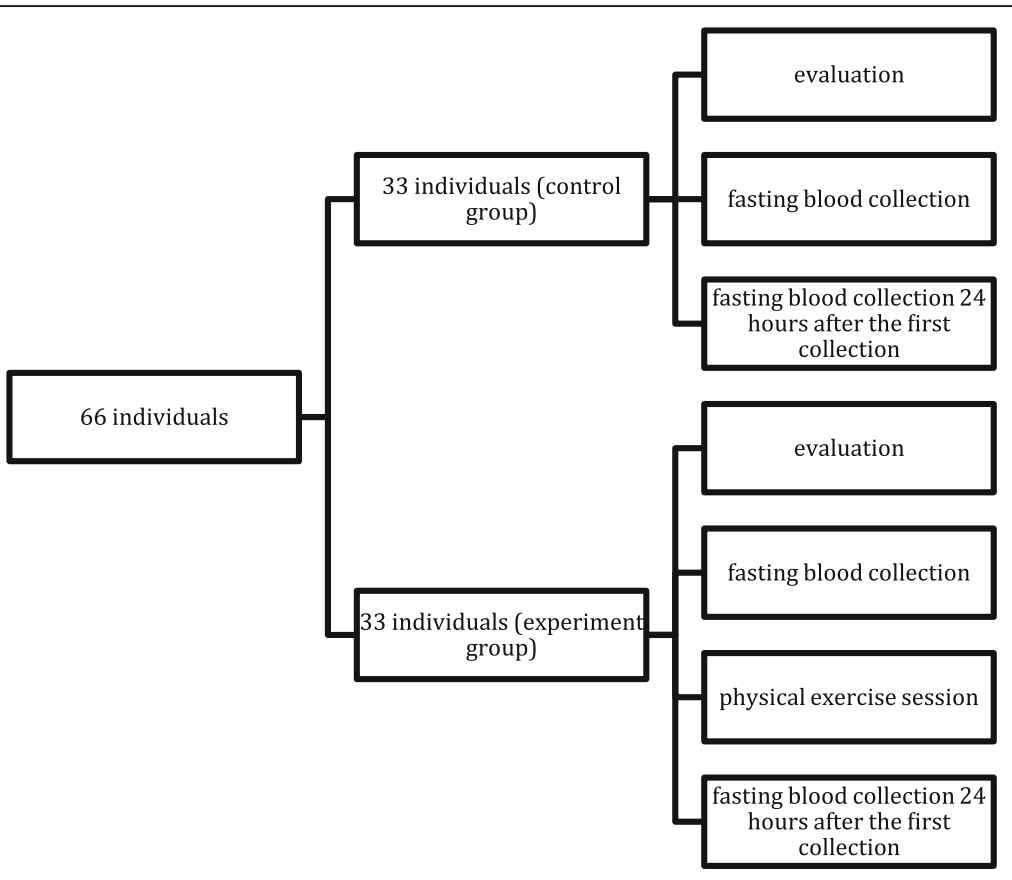

Fig. 1 Flowchart of data collection 
Table 1 Clinical and anthropometric characteristics of the total sample and per group on the first day of blood collection

\begin{tabular}{|c|c|c|c|c|}
\hline VARIABLES & $\begin{array}{l}\text { Total Sample } \\
(n=66)\end{array}$ & $\begin{array}{l}\text { CG } \\
(n=33)\end{array}$ & $\begin{array}{l}\text { EG: } \\
(n=33)\end{array}$ & $p$ \\
\hline Triglycerides (mg/dL) & $94 \pm 43$ & $99 \pm 43$ & $102 \pm 64$ & 0.81 \\
\hline Total Cholesterol (mg/dL) & $162 \pm 32$ & $163 \pm 29$ & $159 \pm 30$ & 0.59 \\
\hline High Density Lipoprotein (mg/dL) & $49 \pm 10$ & $45 \pm 8$ & $49 \pm 10$ & 0.11 \\
\hline Low Density Lipoprotein (mg/dL) & $94 \pm 28$ & $97 \pm 24$ & $89 \pm 26$ & 0.18 \\
\hline Glycemia (mg/dL) & $84 \pm 8$ & $84 \pm 9$ & $82 \pm 8$ & 0.22 \\
\hline Insulin (mclU/mL) & $10 \pm 5$ & $12 \pm 6$ & $8 \pm 5$ & 0.01 \\
\hline Homa IR & $2.4 \pm 1.2$ & $2.9 \pm 1.4$ & $2.0 \pm 1.3$ & 0.01 \\
\hline Homa-Beta & $34 \pm 20$ & $40 \pm 19$ & $27 \pm 18$ & 0.01 \\
\hline
\end{tabular}

CG-Control Group; EG-Experimental Group; ${ }^{*} p<0.05$, Student's- $t$ Test

while in the control group, no change was found in any of the lipid profile variables (Table 4).

In the intergroup comparison, no difference was observed in the variation of triglycerides, total cholesterol, LDL-C, HDL-c and TG/HDL levels, neither in the experimental group nor in the control group (Table 5).

\section{Dsiscussion}

The results of this study demonstrated that low intensity physical exercises in women with excess weight, acutely reduced the serum glycemia, however, it did not change the lipid profile.

Some studies, conducted with other populations and different protocols have corroborated our results and pointed out that/?this type of?/exercise was incapable of improving the lipid profile in an acute manner [4]. However, in the study conducted by Ferguson et al. [14], the correspondence was investigated, between the energetic threshold and the possible changes in the triglyceride levels and concentrations of lipoproteins in trained men after four exercise protocols. The protocols were carried out with caloric expenditures of 800, 1100, 1300 and $1500 \mathrm{kcal}$. Twenty-four hours after performing the

Table 2 Intragroup analysis of glycemic values, insulin and HOMA IR and HOMAbeta

\begin{tabular}{llll}
\hline & Before & After & $P$ \\
\hline EG $(n=33)$ & & & \\
Glucose $(\mathrm{mg} / \mathrm{dL})$ & $97 \pm 6.6$ & $93 \pm 6.6$ & $0.01^{*}$ \\
Insulin $(\mathrm{mcl} / \mathrm{mL})$ & $8 \pm 5.2$ & $8 \pm 5.2$ & 0.99 \\
Homa Index & $2.0 \pm 1.3$ & $1.9 \pm 0.9$ & 0.69 \\
Homa-Beta & $27.9 \pm 18.7$ & $27.6 \pm 18.7$ & \\
CG $(n=33)$ & & & \\
Glucose $(\mathrm{mg} / \mathrm{dL})$ & $97 \pm 8.6$ & $98 \pm 8.8$ & 0.41 \\
Insulin (mclU/mL) & $12 \pm 5.6$ & $12 \pm 5.2$ & 0.78 \\
Homa IR & $2.9 \pm 1.4$ & $2.8 \pm 1.3$ & 0.76 \\
Homa-Beta & 40.7919 .7 & $39.4 \pm 17.1$ & 0.70 \\
\hline
\end{tabular}

EG = Experimental Group; CG = Control Group; *Bidirectional Student's- $t$ Test for paired samples sessions, the HDL was significantly elevated in the exercises with expenditure of 1100,1300 and $1500 \mathrm{kcal}$. Whereas the LDL concentration diminished significantly with an expenditure of $1300 \mathrm{kcal}$; and that of triglycerides, with $800 \mathrm{kcal}$ after one single exercise session. In the same study, it was possible to observe an increase in lipoprotein lipase activity $24 \mathrm{~h}$ after the sessions with caloric expenditure of over $1100 \mathrm{kcal}$, and this remained elevated up to $48 \mathrm{~h}$ after the session using $1500 \mathrm{kcal}$, as these changes coincided with the changes in HDL. In another study, Ferreira et al. [15] also observed significant reduction in post-prandial lipemia in men submitted to different intensities of effort both with caloric expenditure of $500 \mathrm{kcal}$. They verified that both moderate and high intensity exercise presented reduction in post-prandial lipemia. Possibly the caloric expenditure on performing the protocol of this study was not enough to promote these changes.

Nevertheless, the protocol used was effective in reducing glycemia. The knowledge that exercise increases insulin sensitivity, in both the acute and chronic form, served as a basis for explaining the results obtained in this study [16].

Some are the effects promoted by exercise, which explain this result. Physical exercise is known to increase the phosphorylation of insulin receptors (IRS1 and 2), which consequently facilitates the action of insulin [17]. This effect occurs during exercise and may last of up to $16 \mathrm{~h}$ after the exercise [18].

Table 3 Comparison of variation in the glycemic profile in the Control and Exercise Groups

\begin{tabular}{llll}
\hline & CG $(n=33)$ & EG $(n=33)$ & $p$ \\
\hline$\Delta$ Glucose & $0.90 \pm 6.1^{*}$ & $-4.18 \pm 6.3$ & $0.02^{*}$ \\
$\Delta$ Homa-IR & $-0.06 \pm 1.2^{*}$ & $-0.06 \pm 0.9$ & 0.99 \\
$\Delta$ Homa-Beta & $-1.30 \pm 19^{*}$ & $-0.30 \pm 13.8$ & 0.81 \\
$\Delta$ Insulin & $0.00 \pm 5.3^{*}$ & $-0.18 \pm 3.8$ & 0.87 \\
\hline
\end{tabular}

列 for independent samples 
Table 4 Intragroup Lipid Profile Analysis ( $n=33$ )

\begin{tabular}{llll}
\hline & Before & After & $p$ \\
\hline Experimental & & & \\
Total Cholesterol (mg/dL) & $159 \pm 30.3$ & $161 \pm 34.0$ & 0.36 \\
Triglycerides (mg/dl) & $102 \pm 64.4$ & $93 \pm 49.3$ & 0.08 \\
High Density Lipoprotein (mg/dL) & $49 \pm 10.5$ & $51 \pm 10.3$ & 0.04 \\
Low Density Lipoprotein (mg/dL) & $89 \pm 26.4$ & $91 \pm 29.7$ & 0.27 \\
Ratio TG/HDL & $2.2 \pm 1.6$ & $1.9 \pm 1.2$ & 0.06 \\
Control & & & \\
Total Cholesterol (mg/dL) & $163 \pm 29.0$ & $162 \pm 30.9$ & 0.77 \\
Triglycerides (mg/dl) & $99 \pm 42.6$ & $94 \pm 37.4$ & 0.06 \\
High Density Lipoprotein (mg/dL) & $46 \pm 7.7$ & $46 \pm 10.3$ & 0.09 \\
Low Density Lipoprotein (mg/dL) & $97 \pm 23.6$ & $97 \pm 26.8$ & 0.69 \\
Ratio TG/HDL & $2.2 \pm 1.1$ & $2.1 \pm 1.1$ & 0.10 \\
\hline Student's-t test for dependent samples & & &
\end{tabular}

More specifically, in obesity, changes occur in diverse points of the insulin signal transduction pathway. Such as reduction in the concentration and phosphorylation of the insulin receptors [19]. In many cases, this is explained by the higher level of subclinical inflammation in this population [20]. Hypertrophy of the adipose tissue stimulates the production of prof-inflammatory adipokines such as TNF-alfa and diminishes the production of anti-inflammatory substances such as adiponectin. This may consequently diminish insulin sensitivity, since TNF-alfa hinders, and adiponectin favors the action of insulin [21]. On the other hand, this process of physical exercise attenuates the sub-clinical inflammation, and improves the relations between the production of proand anti-inflammatory substances by the adipose tissue [9]. Although studies with only one exercise session have presented controversial results in this population $[22,23]$, thus acute reduction in subclinical inflammation is also a possible mechanism that explains the reduction in glycemia in the EG.

Other mechanisms independent of insulin may also explain the reduction in glycemia in the EG. The increase in bioavailability of chrome that occurs during and after exercise appears as one of the explanations. During exercise the increase in the need of glucose in muscle tissue stimulates the release of chrome that acts

Table 5 Intergroup Analysis of Variation in Lipid Profile

\begin{tabular}{llll}
\hline & Control & Experimental & $p$ \\
\hline$\Delta$ Total Cholesterol & $-1.0(-6.5-3.5)$ & $0.0(-0.4-6.5)$ & 0.32 \\
$\Delta$ Triglycerides & $-4.0(-13.0-4.5)$ & $-5.0(-19.0-11.0)$ & 0.80 \\
$\Delta \mathrm{HDL}$ & $0.0(-1.5-4.1)$ & $0.6(-1.0-2.8)$ & 0.80 \\
$\Delta \mathrm{LDL}$ & $-3.0(-6.5-3.5)$ & $0.0(-4.0-6.5)$ & 0.62 \\
$\Delta \mathrm{TG} / \mathrm{HDL}$ & $-0.1(-0.3-0.1)$ & $-0.1(-0.4-0.1)$ & 0.32 \\
\hline
\end{tabular}

Median (Interquartile Interval); Mann-Whitney Test as adjuvant to insulin. Chrome potentiates the action of insulin, stimulating glucose absorption during and after exercise, increasing the fluidity of the cell membrane to facilitate insulin binding to its receptor [24]. This increase in the blood concentration of chrome may last for hours after exercise. The higher level of calcium release by the sarcoplasmic reticulum also favors glucose transport to the muscle cell [25]. The increase in calcium in the muscle cell cytoplasm initiates and facilitates activation of the molecules involved in the intracellular signaling cascade of glucose transport [25].

A mechanism that is also independent of insulin is that of the AMPK enzyme (AMP-activated protein kinase). This enzyme stimulates glucose transport in the skeletal muscle. Its activation results in a reduction in the stocks of intracellular glucose. In the situation in which the AMP:ATP ratio increases, an increase in AMPK activity also occurs. This increase in AMPK activity in response to a need of generating ATP, particularly during but also after physical exercise, promotes the translocation of vessels containing Glut-4 [26]. This finally facilitates the influx of glucose into the muscle cell independently of insulin.

Lastly, another possibility may be associated with exercise-induced changes in hemodynamics. A single session of exercise is known to diminish sympathetic activity and increase muscle blood flow in the period after exercise. It is interesting to note that after a single session of exercise, sympathetic action diminishes and muscle vasodilatation increases. These and other hemodynamic changes may also contribute to increasing insulin sensitivity after exercise [27]. Moreover, physical exercise stimulated the production of endothelial nitric oxide synthase (eNOS), by means of shear stress on endothelial cells during exercise [28]. At the same time it inhibits a series of molecules that favor the production of Inducible nitric oxide synthase (iNOS). While the former is related to the higher level of vasodilatation of the active musculature [29], Inducible nitric oxide synthase is associated with insulin resistance [30]. Studies with rats have pointed out that a single session was capable of promoting a reduction in this enzyme and consequently increase insulin sensitivity.

Some of points of this study should be emphasized. The authors observed that although the study population was randomly divided, the CG presented higher insulin, HomaIR and Homa-Beta values than the EG. Could this have influenced the results obtained? Individuals with a lower level of insulin sensitivity are known to present a higher concentration of plasma insulin in an attempt to maintain an adequate supply of glucose within the muscle and adipose cells. This was perceived when the HOMABeta values rose, demonstrating a higher level of insulin production by the beta-pancreatic cells. 
Individuals who presented this condition had greater difficulty with metabolizing lipids, because when insulin binds to its muscle membrane receptors, it stimulates the action of lipoprotein lipases that play a fundamental role in the metabolism of triglycerides and plasma lipoproteins. However, as observed in Table 1, the fasting lipid profile values did not differ between the groups. Whereas, as observed in Table 4, in the EG there was a significant reduction in LDL and the Ratio TG/HDL, while no reduction was observed in the CG. Nevertheless, this reduction was not sufficient to show difference in the intergroup comparison.

Among the limitations of this study, the authors point out a single 12-h time interval of observation, and absence of caloric expenditure above $250 \mathrm{Kcal}$ for different comparisons. With regard to physical activity, it is known that factors such as time of observation and energy expenditure may influence the plasma limit response [31]. The authors observed that this study signals the responses to a caloric expenditure and in a specific time, and in this case no change was identified in the lipid response; which does not mean that these responses did not occur in later time intervals or in higher caloric expenditures. Comparisons of different protocols in the acute and sub-acute stage of physical exercise must be tested so that lipid responses to different energy expenditures and in different time intervals may be shown after the physical exercise session.

\section{Conclusion}

In overweight women, the sub-acute effect of low intensity physical exercise is capable of modifying the glycemic levels, not interfering in the lipid response and insulin resistance variables.

\section{Acknowledgments}

This work was supported by National Council for Scientific and Technological Development (CNPQ).

\section{Funding}

This work was supported by National Council for Scientific and Technological Development (CNPQ).

\section{Availability of data and materials}

The datasets used and/or analysed during the current study are available from the corresponding author on reasonable request.

\section{Academic connection}

This article is part of the doctoral thesis of Djeyne Silveira Wagmacker (Doctoral Program in Human Health), of the Bahian School of Medicine and Public Health, Salvador, BA - Brazil.

\section{Authors' contribution}

DSW, LEAR and AML conceived the idea and drafted the manuscript; ASF, JBM and SKAM worked on data collection; DSW and JP also performed the statistical analysis and AML and LEAR was also the supervisor. All authors read and approved the final manuscript.

\section{Ethics approval and consent to participate}

The Research Ethics Committee of the Adventist Faculty of Bahia (CEP/FADBA), recognized by the National Commission for Research Ethics (CONEP/MS), analyzed the research protocol. Title: Influences of physical activity on the trans fatty acid profile in the serum of individuals with changes in body weight. CAAE: 34,017,514.5.0000.0042. Researcher Responsible: Djeyne Silveira Wagmacker. This project was APPROVED in its ethical and scientific aspects according to the Guidelines established in Resolution 466/12 of the National Health Council. DATE OF APPROVAL: 05/08/2014.

\section{Consent for publication}

The authors declare that the data met the criteria for authorship, as established by the International Committee of Medical Journal Editors and that the local Bioethics Committee of our center approved the protocol study and all patients provided informed consent.

\section{Competing interests}

The authors declare there is no pertinent conflict of interest.

\section{Publisher's Note}

Springer Nature remains neutral with regard to jurisdictional claims in published maps and institutional affiliations.

\section{Author details}

${ }^{1}$ College Adventist Bahia, Cachoeira, Bahia, Brazil. ${ }^{2}$ Bahian School of Medicine and Public Health, Science Development Foundation of Bahia, Bahia, Brazil. ${ }^{3}$ Catholic University of Salvador, Salvador, Bahia, Brazil. ${ }^{4}$ Present Address: Br 101, Km 197, cx postal 18, Salvador, Bahia, Brazil.

Received: 17 August 2017 Accepted: 26 October 2017

Published online: 19 December 2017

\section{References}

1. Petto J, Silveira DW, Santos AC, Seixas CR, Santo DG, Oliveira FT, et al. Postprandial lipemia and subclinical inflammation on active women taking oral contraceptive. Int J Cardiovasc Sci. 2015;28(3):215-23.

2. Magkos F, et al. Lipid metabolism response to a single, prolonged bout of endurance exercise in healthy young men. Am J Physiol Endocrinol Metab. 2006;290:E:355-E362.

3. Cambri LT, Decimo JP, Souza M, Oliveira FR, Gevaerd MS. Efeito agudo e crônico do exercício físico no perfil glicêmico e lipídico em diabéticos tipo 2. Motriz. 2007;13(4):238-48.

4. Bodel NG, Gillum T. 90 Minutes of Moderate-Intensity Exercise does not Attenuate Postprandial Triglycerides in Older Adults. Int J Exerc Sci. 2016; 9(5):677-84

5. Thackray AE, Barrett LA, Tolfrey K. High-Intensity Running and Energy Restriction Reduce Postprandial Lipemia in Girls. Medicine \& Science in Sports \& Exercise. 2016:48(3):402-11.

6. Valdés PA, Ramos DC, Mehta R, Hernandez LM, Bautista IC, Mendez OP, et al. Factors associated with postprandial lipemia and apolipoprotein A-V levels in individuals with familial combined hyperlipidemia. BMC Endocr Disord. 2014;14:90

7. Gill JM, Hardman AE. Exercise and postprandial lipid metabolism: an update on potential mechanisms and interactions with high-carbohydrate diets. J. Nutr. Biochem. 2003;14:122-32.

8. Petto J, Batista AKMS, Oliveira CS, Ladeia AMT. Efeito agudo do exercício físico na lipemia pós-prandial: revisão. Rev Bras Fisiologia Exercício. 2012;11:111-4.

9. Matsudo S, Araújo T, Marsudo V, Andrade D, Andrade E, Oliveira C, Braggion G. Questinário internacional de atividade física (IPAQ): estudo de validade e reprodutibilidade no Brasil. Rev bras ativ fís saúde. 2001;6(2):05-18.

10. Matthews DR, Hosker JP, Rudenski AS, Naylor BA, Treacher DF, Turner RC. Homeostasis model assessment: insulin resistance and beta-cell function from fasting plasma glucose and insulin concentrations in man. Diabetologia. 1985;28:412-9.

11. Ep P, Mestek ML, Mahurin AJ. Postprandial triglyceride responses to aerobic exercise and extended-release niacin. Am J Clin Nutr. 2008:88(4):30-7.

12. Chen MJ, Fan X, Moe ST. Criterion-related validity of the Borg ratings of perceived exertion scale in healthy individuals: a meta-analysis. J Sports Sci. 2002;20:873-99. 
13. Departamento De Aterosclerose Da Sociedade Brasileira De Cardiologia. IV Diretriz Brasileira Sobre Dislipidemias e Prevenção da aterosclerose. Arquivos Brasileitos de Cardiologia - Volume 88, Suplemento I, Abril 2007.

14. Ferguson MA, Alderson NL, Trost SG, Essig DA, Burke JR, Durstine JL. Effects of four different single exercises sessions on lipids, lipoproteins, and lipoprotein lipase. J Appl Physiol. 1998;85:1169-74.

15. Ferreira AP, Ferreira CB, Souza VC, Cordova COA, Silva CB, Nobrega OT, Franca NM. The influence of intense intermittent versus moderate continuous exercise on postprandial lipemia. Clinics. 2011;66(4):535-41.

16. Goodyear $\sqcup$, Kahn BB. Exercise, glucose transport and insulin sensitivity. Annu Rev Med. 1998:49:235-61.

17. Hayashi T, Wojtaszewski JF, Goodyear LJ. Exercise regulation of glucose transport in skeletal muscle. Am J Physiol. 1997;273(6):E1039-51.

18. Pauli JR, Ropelle ER, Cintra DE, Carvalho-filho MA, Moraes DSCT, et al. Acute physical exercise reverses S-nitrosation of the insulin receptor, insulin receptor substrate 1, and protein kinase B/Akt in dietary induce obese Wistar rats. J Physiol. 2008;586:659-71.

19. Dandona P, Aljada A, Bandyopadhyay A. Inflammation: the link between insulin resistance, obesity and diabetes. Trends immunology. 2004;25(1):4-7. 31

20. Waki $\mathrm{H}$, Tontonoz P. Endocrine functions of adipose tissue. Annu Rev PatholMech Dis. 2007;2:31-56.

21. Petto J, Santos ACN, Motta MT, Filho RST, Santo DGCE, Ribas JLL, Ladeia AMT. Adiponectina: Caracterização, Ação Metabólica e Cardiovascular. Int J Cardiovasc Sci. 2015;28(5):424-32.

22. Fischer $C P$, Berntsen $A$, Perstrup LB, Eskildsen P, Pedersen BK. Plasma levels of interleukin-6 and C-reactive protein are associated with physical inactivity independent of obesity. Scand J Med Sci Sports. 2007;17(5):580-7.

23. Wagmacker DS, Souza KK, da Graça JV, Barreto GC, Macêdo PCS, Ferreira TF, et al. Acute effect of moderate intensity physical exercise on postprandial hyperlipaemia of individuals with central obesity. Health 4 2012; 1546-1550.

24. Evans GW, Bowman TD. Chromium picolinate increases membrane fluidity and rate of insulin internalization. J Inorg Biochem. 1992;46:243-50.

25. Holloszy JO, Constable SH, Young DA. Activation of glucose transport in muscle by exercise. Diabetes Metab Rev. 1986;1:409-24.

26. Hardie DG, Carling D. The AMP-activated protein kinase: fuel gauge of the mammalian cell? Eur J Biochem. 1997;246(2):259-73.

27. Bisquolo VA, Cardoso CG Jr, Ortega KC, Gusmao JL, Tinucci T, Negrao CE, et al. Previous exercise attenuates muscle sympathetic activity and increases blood flow during acute euglycemic hyperinsulinemia. J Appl Physiol. 2005; 98(3):866-71.

28. Gross SS, Wolin MS. Nitric oxide: pathophysiological mechanisms. Annu Rev Physiol. 1995;57:737-69.

29. Carvalho-Filho MA, Ueno M, Carvalheira JB, Velloso LA, Saad MJ. Targeted disruption of iNOS prevents LPS-induced S-nitrosation of IRbeta/IRS-1 and Akt and insulin resistance in muscle of mice. Am J Physiol Endocrinol Metab. 2006;291(3):E476-82

30. Sugita $H$, Kaneki M, Tokunaga E, Sugita M, Koike C, Yasuhara S, et al. Inducible nitric oxide synthase plays a role in LPS-induced hyperglycemia and insulin resistance. Am J PhysiolEndocrinol Metab. 2002;282:E386-94.

31. Petto J, ARMS B, Oliveira CS, AMT L. Efeito agudo do exercício físico na lipemia pós-prandial. Revisão Rev Bras Fisiol Exercício. 2012;11:111-4.

\section{Submit your next manuscript to BioMed Central and we will help you at every step:}

- We accept pre-submission inquiries

- Our selector tool helps you to find the most relevant journal

- We provide round the clock customer support

- Convenient online submission

- Thorough peer review

- Inclusion in PubMed and all major indexing services

- Maximum visibility for your research

Submit your manuscript at www.biomedcentral.com/submit

) Biomed Central 